\title{
Oceanic Zircon as A petrogenetic indicator
}

\author{
Aranovich L.Y. ${ }^{1}$, Bortnikov N.S. ${ }^{1,2}$, \\ Borisov A.A. ${ }^{1,3}$ \\ 123 \\ ${ }^{1}$ Institute of Geology of Ore Deposits, Petrography, \\ Mineralogy and Geochemistry RAS, Staromonetnyi per. \\ 35,119017 Moscow, Rassia, lyaranov@igem.ru \\ 2bns@igem.ru \\ ${ }^{3}$ aborisov.igem@gmail.com
}

Morphology and geochemical features of zircon separates from a variety of rocks from MidAtlantic Ridge have been studied with a variety of methods. Magmatic zircon $(\mathrm{Zrn})$ in the gabbroids crystallized from differentiating magmatic melt in a number of episodes, as follows from the systematic rim-ward increase in the Hf concentration, which is related to the $\mathrm{Zr}$-Hf fractionation during $\mathrm{Zrn}$ growth [Aranovich, Bortnikov, Petrology, 2018, 26, 115-120.]. These tendencies are also discernible in $Z r n$ from the OPG. Zrn in the OPG is depleted in REE compared to the least modified Zrn in the gabbro, suggesting that the OPG were derived via partial melting of gabbro in the presence of seawater-derived concentrated aqueous salt fluid. Another reason for the REE depletion might be simultaneous crystallization of zircon and apatite. The CL-dark sectors, which are found in practically all magmatic Zrn grains, have Y/P (a.p.f.u.) $>>1$, most likely resulted from $\mathrm{OH}$ accommodation in the $\mathrm{Zrn}$ structure, a fact suggesting that the OPG parental melt contained water. High-temperature hydrothermal processes induced partial to complete recrystallization of Zrn (via dissolution - re-precipitation), a process that was associated with ductile and brittle deformations of the zircon-hosting rocks. The morphology of the hydrothermal $\mathrm{Zrn}$ varies depending on the $\mathrm{pH}$ and silica activity in the fluid. The early hydrothermal transformations of the $\mathrm{Zrn}$ resulted in enrichment in $\mathrm{La}$ and other LREE, except only Ce, whose concentration, conversely, decreases compared to that of the unmodified magmatic Zrn. Reduction in both bulk Ce and $\mathrm{Ce}^{*}$ is related to the reducing nature of the hydrothermal fluid. The work is supported by the Russian Scientific Fund (project № 18-17-00126) 